\title{
La ética en la Revolución Tecnológica
}

\section{Alejandro Serrano Caldera Filósofo}

La Revolución Tecnológica ha producido transformaciones profundas, cambios en el mundo que han conducido a un cambio de mundo. Estas transformaciones cualitativas de naturaleza científica y tecnológica han incidido y continúan incidiendo sobre el conjunto de valores sociales, culturales y éticos que constituyen la plataforma moral de una época y el repertorio de visiones y comportamientos de la sociedad en un tiempo y lugar determinados.

La acumulación de los cambios en el mundo produce un cambio de mundo, de igual manera que la acumulación de cambios cuantitativos produce un cambio cualitativo. La sociedad de nuestro tiempo está cambiando cualitativamente: la masificación, la sociedad digital, el poder de los medios de comunicación, la lógica del consumo, la velocidad de los medios de transporte, la globalización financiera, pero también del narcotráfico, de la corrupción, del terrorismo, el endurecimiento de las micro sociedades y etnoculturas, la reestructuración del poder mundial mediante la consolidación del núcleo duro del poder político, financiero y militar, la reunificación en una sola unidad y en una sola estrategia de la geopolítica y la geoeconomía, el doble fenómeno de globalización y uniformidad, por un lado, y su correlativo de fragmentación, por el otro, constituyen una especie de mapa dinámico y conflictivo de la vida de nuestro tiempo.

Todos estos hechos y acontecimientos están transformando -si no lo han hecho ya por lo menos al nivel de una generación- su escala de valores, su visión del mundo y de la vida y sus categorías éticas que rigen su comportamiento. Los cambios en la realidad producen cambios en la conciencia de las personas, de los pueblos y de las épocas. La tecnología es una maravillosa creación del espíritu humano, no obstante, a pesar de ello, es un medio a través del cual deben realizarse los más altos propósitos del ser humano y de la sociedad, pues la persona es y continúa siendo el fin de todo desarrollo, el sujeto y destinatario del proceso de la historia. Los avances de la tecnología exigen por ello la construcción de una ética compuesta de valores y principios en cuyo cumplimiento y observancia encuentran su propia dignidad los avances tecnológicos y, sobre todo, el propio ser humano que es y será siempre el objetivo esencial y final del desarrollo. Por esa razón, la primera exigencia frente a la tecnología es su aplicación conforme a determinados parámetros éticos, y la primera condición de una ética es su carácter incluyente, equitativo y humano.

Las últimas décadas del Siglo XX y estos años del siglo XXI, han sido testigos de un intenso -y quizás no suficientemente percibido- debate de filosofía política, de ética y de teorías del desarrollo de la sociedad contemporánea.

Desde inicios de la década de los años 70 del siglo pasado, a raíz del Consenso de Washington y la Declaración de Kyoto, se sentaron las bases de lo que se conoce como neoliberalismo, 
al supeditar la democracia política al capitalismo monopólico, el Estado al mercado y al refirmar la libertad económica como la libertad fundamental de la cual depende la propia libertad individual.

En el siglo XIX fue la sustitución del liberalismo filosófico y político, fundado en la razón, en la voluntad y en la libertad individual, por el liberalismo económico, determinado por las leyes del mercado, que vino presentado como la realización del derecho natural en la historia, con leyes autónomas e infalibles frente a las que al Estado sólo correspondía el papel de facilitador, versión remozada del Estado abstencionista del siglo XIX.

Más que de un nuevo liberalismo, se trataba de las ideas del viejo liberalismo debidamente maquilladas para enfrentar los retos de la revolución tecnológica y de la sociedad digital, pero conservando la misma versión inflexible de mercado total como sujeto y destinatario de la historia, o mejor aún, como la historia misma, a la que quedaban supeditadas todas las demás expresiones del acontecer humano individual y colectivo, en el plano de la política, la economía, las finanzas, la cultura, las relaciones sociales, entre otras. Se estaba, entonces, ante lo que Franz Hinkelammert, uno de sus críticos más severos, llamó la idolatría de mercado y el filósofo y teólogo francés, Roger Garaudy, llamó el monoteísmo de mercado.

Desde 1970 -fecha del debilitamiento de la vigencia del pensamiento de John Maynard Keynes como filosofía oficial del capitalismo, que aunque iniciada a finales del siglo XIX se reafirma con el Keynesianismo, sobre todo en 1929, como respuesta a la crisis de la bolsa de valores y, en general del capitalismo mundial- se inicia y consolida esta especie de teología económica y financiera que se va a constituir en el dogma de fe de todo proceso de desarrollo. El Estado no será más que la correa de trasmisión de los dictados infalibles del mercado, el poder económico, y por supuesto político, estará en las corporaciones transnacionales y en sus filiales nacionales y locales. Mientras menos Estado, mejor.

No obstante, el mismo proceso neoliberal demostró la necesidad del Estado al servicio de los poderes económicos para garantizar la tutela de intereses corporativos y de intereses económicos nacionales, lo mismo que la inevitable adaptación de las instituciones para poder responder adecuadamente a los procesos regionales y subregionales de integración de mercados, los que, sin la estructura institucional apropiada, verían severamente afectada su eficacia y seriamente limitada su posibilidad de desarrollo y expansión. Se pasó entonces a la etapa de reforma del Estado y sus instituciones para adecuarlas a las políticas económicas, financieras y de mercado, en general.

Posteriormente, y a raíz de los atentados terroristas del 11 de septiembre de 2001, el Estado recuperó su poder y vigencia como el instrumento capaz de combatir el terrorismo y el narcotráfico, funciones que el mercado por si solo evidentemente no podía cumplir. El Estado vuelve así al primer plano, no como mecanismo que contribuya a establecer y garantizar las políticas sociales, sino como un instrumento para los nuevos combates del siglo XXI.

Se produce así una reunificación del núcleo duro del poder mundial el que se apoya en el Estado y en el mercado, en la función pública y en la iniciativa privada y, por supuesto, en el poder militar y en los ejércitos. Estado, mercado, ejército, interés público e interés privado, integran así una unidad necesariamente complementaria para el ejercicio del poder. 
Mientras tanto, un pensamiento alternativo al neoliberalismo se ha venido estructurando respaldado no sólo por sus propias ideas, sino por los fracasos en las situaciones económicas y sociales de los países menos favorecidos, los que han visto incrementada su pobreza a raíz de los fracasos y repercusiones sociales negativas de los ajustes estructurales. Además, el pensamiento filosófico, político y aun religioso, ha desarrollado una crítica consistente entre la que habría que mencionar la Encíclica Centésimo Año, de 1991, del Papa Juan Pablo II, en la que reintrodujo el término "Capitalismo Salvaje", usado cien años antes por el Papa León XIII, en su Encíclica Rerum Novarum.

Frente al neoliberalismo surge un nuevo pensamiento que proclama la necesidad del Estado y de las instituciones como condición ineludible para cualquier tipo de desarrollo. No hay posibilidad de desarrollo económico y social sin un Estado con instituciones sólidas, modernas e independientes. La historia de los países más avanzados, demuestra esta realidad. La reingeniería institucional deviene, pues, en la condición de cualquier forma de desarrollo.

Junto a la idea del predominio institucional, y al lado de una especie de neokeynesianismo, surge con fuerza el pensamiento inspirado en el Estado Social de Derecho y en la economía social de mercado, de factura preferentemente social demócrata, lo mismo que las doctrinas del contrato social, la participación ciudadana y el fortalecimiento de la sociedad civil como garantías para establecer y mantener una sociedad y un Estado libre, democrático, justo, solidario y equitativo.

Dentro de estas profundas transformaciones en el pensamiento económico, político y social contemporáneo habría que mencionar de manera principal y prioritaria, y ligada al contexto de la sociedad digital, los esfuerzos teóricos y prácticos por construir la sociedad de la información como un paso necesario para llegar a la sociedad del conocimiento, definida como un desafío mundial para el nuevo milenio.

La Declaración de Principios de la Cumbre Mundial sobre la Sociedad de la Información, celebrada en Ginebra en el año 2003, establece como desafío esencial "Encauzar el potencial de la tecnología de la información y la comunicación para promover las metas del desarrollo de la Declaración del Milenio", entre las que se mencionan, "Erradicar la extrema pobreza y el hambre, lograr una educación primaria universal, promover la igualdad de género y la habilitación de las mujeres, reducir la mortalidad infantil, mejorar la salud materna...", entre otras muchas, al tiempo que se reitera el compromiso para alcanzar "El desarrollo sostenible y las metas de desarrollo convenidas, que se señalan en la Declaración de Johannesburgo y en el Plan de Aplicación del Consenso de Monterrey, y otros resultados de las Cumbres pertinentes de las Naciones Unidas".

La aplicación de la tecnología más avanzada al logro del Desarrollo Humano sostenible formula una ética cuyos aspectos más relevantes se encuentran contenidos en los tratados internacionales de derechos humanos que de esta forma se constituyen en la filosofía moral de esta época.

Una serie de valores dan sentido específico a esta ética de la sociedad de la información. El primero de ellos es el de garantizar el carácter inclusivo que permita la participación 
de todos en ella, pues de lo contrario la tecnología en lugar de ser el medio integrador se pervertiría en un instrumento de acentuación de la brecha digital y, en consecuencia, de profundización de la brecha económica, social, educativa y cultural entre los pueblos e inclusive entre los ciudadanos de un mismo país.

La información y el conocimiento constituyen un bien público y son esenciales a la educación, la cultura y la democracia a tal extremo que no será posible una democracia real sin una democracia digital. De ahí que la Tecnología de la Información y Comunicación, TIC, entendida como estrategia y como conjunto de medios y herramientas para el intercambio de la información que produce el conocimiento, se vuelve un instrumento imprescindible para realizar la ética del desarrollo humano sostenible y los valores que lo conforman. Estos valores son la libertad, la igualdad, la solidaridad, la tolerancia, el respeto a la naturaleza, la responsabilidad común, el respeto a la diferencia y el reconocimiento del otro, todos los que nos llevan a reafirmar que el sujeto esencial del desarrollo es el ser humano y la sociedad en su dignidad integral, en su libertad y en sus derechos reafirmados en la justicia y en el imperio de la ley.

La nueva ética, o mejor, la ética para la nueva sociedad, tiene que ser la ética de la unidad en la diversidad en la que todos los seres humanos, en virtud de la dignidad esencial que les corresponde, tienen el derecho pleno de participar en el disfrute de los bienes materiales, culturales y morales de la sociedad de nuestro tiempo. 